\title{
Application of a computational model for complex fluvial ecosystems:The population dynamics of zebra mussel Dreissena polymorpha as a case study
}

\author{
$\mathrm{M}^{\mathrm{a} A ̀ n g e l s ~ C o l o m e r}{ }^{\mathrm{a}, *}$, Antoni Margalida ${ }^{\mathrm{b}, \mathrm{c}}$, Luís Valencia ${ }^{\mathrm{d}}$, Antoni Palau ${ }^{\mathrm{e}}$ \\ a Department of Mathematics, Faculty of Life Sciences and Engineering, University of Lleida, Av. Alcalde Rovira Roure, 191, Lleida 25198, Spain \\ ${ }^{\mathrm{b}}$ Department of Animal Production (Division of Wildlife), Faculty of Life Sciences and Engineering, University of Lleida, Av. Alcalde Rovira Roure 191, Lleida 25198, Spain \\ ${ }^{\mathrm{c}}$ Division of Conservation Biology, Institute of Ecology and Evolution. University of Bern. Baltzerstrasse 6, 3012, Bern, Switzerland \\ d ResearchGrouponNaturalComputing,DepartmentofComputerScienceandArtificialIntelligence,UniversityofSevilla,Avda.ReinaMercedess/n,Sevilla 41012,Spain \\ e Dirección de Medio Ambiente y Desarrollo Sostenible (Endesa) Ctra, Tarragona Km 89300, Magraners (Lleida) 25191, Spain
}

Keywords:

Biological invasions

Hydroecological processes

Invasive species

Management actions

Population dynamic

P-systems

Zebra mussel
A B S T R A C T

The potential and adaptive flexibility of population dynamic P-systems (PDP) to study population dynamics suggests that they may be suitable for modelling complex fluvial ecosystems, characterized by a composition of dynamic habitats with many variables that interact simultaneously. Using as a model a reservoir occupied by the zebra mussel Dreissena polymorpha, we designed a computational model based on P systems to study the population dynamics of larvae, in order to evaluate management actions to control or eradicate this invasive species. The population dynamics of this species was simulated under different scenarios ranging from the absence of water flow change to a weekly variation with different flow rates, to the actual hydrodynamic situation of an intermediate flow rate. Our results show that PDP models can be very useful tools to model complex, partially desynchronized, processes that work in parallel. This allows the study of complex hydroecological processes such as the one presented, where reproductive cycles, temperature and water dynamics are involved in the desynchronization of the population dynamics both, within areas and among them.

The results obtained may be useful in the management of other reservoirs with similar hydrodynamic situations in which the presence of this invasive species has been documented.

\section{Introduction}

The design of computational models and the development of robust tools to simulate spatial and population trends is essential for decision-making in the management of ecological systems (Johnson and Gillingham, 2005; Van Nes and Scheffer, 2005). Various modelling paradigms exist for simulating population dynamics, depending on the basic elements chosen for the analysis (Lindenmayer et al., 1995). Among the most widely used paradigms, we can highlight the models based on differential equations, which simulate average concentrations and fluxes of specific variables in controlled volumes. However, the complexity

\footnotetext{
* Corresponding author. Tel.: +0034973003721.

E-mail addresses: colomer@matematica.udl.es (M. Colomer),

antoni.margalida@iee.unibe.ch, amargalida@prodan.udl.cat (A. Margalida),

lvalencia@us.es (L. Valencia), antonio.palau@endesa.es (A. Palau).
}

of some models requires the inclusion of a large number of parameter values that are sometimes uncertain, with these models being very sensitive to these parameters (Ray and Burgman, 2006; Makler-Pick et al., 2011).

The amount of data and current knowledge regarding many processes have led to a change in modelling requirements, making it necessary to use more complex models adapted to new technological advances (Fisher and Henzinger, 2007). Some computational models have been developed in the last few decades, such as cellular automata, agent-based models and neural networks, which allow the successful study of complex non-linear problems (Cury et al., 2005; Grimm et al., 2005).

P systems are bio-inspired models sharing a number of features with agent-based models. However, their hierarchical structure and the presence of different environments and areas makes them more appealing in terms of expressive power, allowing the study of more complex problems in a simpler way. P systems are inspired by the functioning of living cells, presenting a compartmentalized 
structure, and are modular systems that work in parallel (Păun, 1998; Păun et al., 2010). They are relatively simple individualbased systems, using some biological parameters that can be obtained experimentally or through references as input (Cardona et al., 2009, 2010; Colomer et al., 2011; Margalida et al., 2011; Margalida and Colomer, 2012). The performance and adaptive flexibility of P systems to study population dynamics (Colomer et al., 2013) suggests that they may be suitable for modelling complex fluvial ecosystems, consisting of a mosaic of dynamic habitats with many variables interacting simultaneously. In addition to an exhaustive knowledge of the biology and behaviour of the target species, in these types of river systems it is essential to understand how the movement of fluids affects the dynamics and distribution of aquatic organisms. In this way, relevant hydraulic parameters can be introduced into models that will enable decision-making in the management of these types of river and reservoir systems (Daraio et al., 2010).

In this work, a fluvial reservoir (Riba-roja-Ebro river, NE Spain) ecosystem is studied, focusing on the zebra mussel Dreissena polymorpha (Pallas, 1771). A computational model is applied to assess the population dynamics of larvae of this species. Zebra mussel is an invasive species in Europe and North America and has spread rapidly throughout Europe over the last decade (Karatayev et al., 2002; Minchin et al., 2005; Strayer 2009). The invasion of zebra mussels into a new aquatic ecosystem causes several major ecological changes, still poorly quantified, such as effects on optical characteristics of the water column, autochthonous species composition and cycling of nutrients and organic matter, among others (Ludyanskyi et al., 1993; O'Neill, 1996 Palau et al., 2003; Ward and Ricciardi, 2007; Higgins et al., 2008; Davis, 2009). It also impacts water use very significantly increasing operating costs and maintenance of hydraulic works, such as in the case of collapsed drains and water pipes (with additional economic costs of maintenance such as cleaning activities and water treatment), loss of attraction and rejection by tourists of recreation zones associated with fishing, sailing or swimming (MacMahon and Tsou, 1990; Jenner et al., 1998; Pimentel et al., 2005; Oreska and Aldrige, 2011).

The rapid expansion of the zebra mussel, and its important ecological and socio-economic effects (Lee et al., 2007; Adams and Lee, 2012), have led to numerous studies, most of them focused on the study of the biology and ecology of the species, geographical dispersion and methods to eradicate or control the species (Wolfram, 1994; Schneider et al., 1998; Morales et al., 2006; Timar and Phaneuf, 2009; Hallstan et al., 2010; Strayer, 2009; Higgins and Vander Zanden, 2010; Palau et al., 2010; Strayer et al., 2010; Sanz-Ronda et al., 2013). To the contrary, works describing variations in zebra mussel population over time at a single site are less abundant (e.g. Burlakova et al., 2006; Strayer and Malcom, 2006; Cassagrandi et al., 2007). The inherent characteristics of the species along with reservoir operations make the study of the population dynamics of zebra mussels an ecologically complex problem. It is therefore difficult to model by means of classical tools extensively used to study population dynamics, such as differential equations or multiagent models. For example, multiagent models require the strict sequencing of the processes being modeled, which is impossible to achieve in the studied scenario.

The main goal of this work is the design of a computational model based on P systems to study the population dynamics of zebra mussel in a reservoir in order to develop an action plan to eradicate or control this invasive species. Using as a model the Riba-roja reservoir (NE Spain), we propose to simulate, with sufficient accuracy, the population dynamics of zebra mussel larvae, in order to evaluate how the management of this reservoir can serve to control or eradicate this invasive species. The population dynamics of this species in the Riba-roja reservoir was simulated under different scenarios ranging from the absence of water flow change to a daily variation with different flow rates, to the actual hydrodynamic situation of an intermediate flow rate. The results obtained may be useful in the management of other reservoirs with similar hydrodynamic situations (i.e., humanmanaged) in which the inputs and outputs of water are controlled and the presence of this invasive species has been documented.

\section{Methods}

\subsection{The study species}

Zebra mussel is an aquatic bivalve mollusk, originally described in a tributary of the Ural River in the Caspian Sea Basin, and is often used as an example supporting the meltdown hypothesis (Ricciardi, 2001; Simberloff and Von Holle, 1999). This species was documented in the lower Ebro River (Spain) in 2001 (RuízAltaba et al., 2001). It is considered an opportunistic species with the ability to settle in a wide variety of aquatic habitats (Palau et al., 2010; Sanz-Ronda et al., 2013). It has a rapid life cycle featuring a huge reproductive potential, along with a high larval mobility, thus implying great dispersal capability (Margalef, 1977; Ackerman et al., 1994; Claudi and Mackie, 1994).

Zebra mussels usually have an average life expectancy of 2-3 years. However, some authors estimate 3-9 years, and some studies suggest even higher numbers, up to 15 years (Ludyanskyi et al., 1993). Because individuals over 3 years old are scarce in the Riba-roja reservoir, we assumed 3 years as the life expectancy.The life cycle of $D$. polymorpha comprises two main stages: the first (larvae) takes place in the water column as a planktonic form, becoming sessile (benthic form) in the second stage (youth and adults).

Zebra mussels are a dioecious species, with a sex ratio of about $1: 1$. The number of eggs produced by female individuals per cycle depends on its size, which is influenced by age (Smit et al., 1992; Chase and Bailey, 1999). See Strayer and Malcom (2006) for a presentation of measurements of size according to the age.

Different authors (Walz, 1978; Sprung, 1992; Strayer and Malcom, 2006) estimate the number of eggs, $Z$, as a function of shell length, $Y$, according to the formula:

$Z=0.4 Y^{4.4}$

Because specific data in the study area are not available, we assumed the previous relationship observed by some authors in different environment conditions.

Larvae remain in the water column for about 15-28 days (Ackerman et al., 1994; Jenner et al., 1998), or according to other authors about 3-5 weeks (Claudi and Mackie, 1994) depending on the temperature of the water and other environmental conditions. For the Riba-roja reservoir, according to Palau et al. (2003) larvae remain in the water column for 28 days. Some of the larvae inside the water column are preyed upon by adult individuals, such that the higher the density of adults, the lower the number of larvae that survive.

The recruitment of young mussels can be calculated as a function of the density of adult individuals (Strayer and Smith, 1996):

$R=-2 X+1, X \leq 0.5$

with $R$ being the ratio of recruited larvae and $X$ the ratio of population in relation to the maximum carrying capacity. If the population exceeds $50 \%$ of the carrying capacity, the recruitment is $0 \%$.

For the Riba-roja reservoir, no specific data exist about recruitment, although density-dependent regulations in 
a)

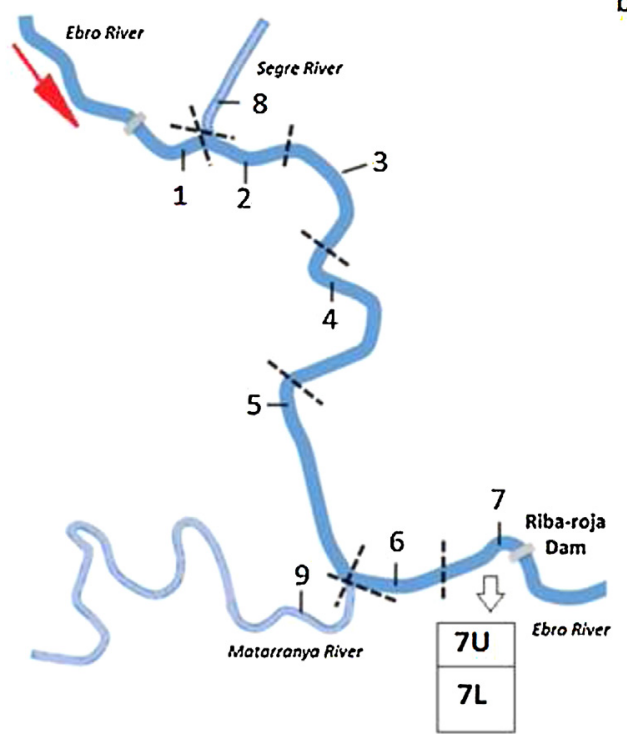

b)

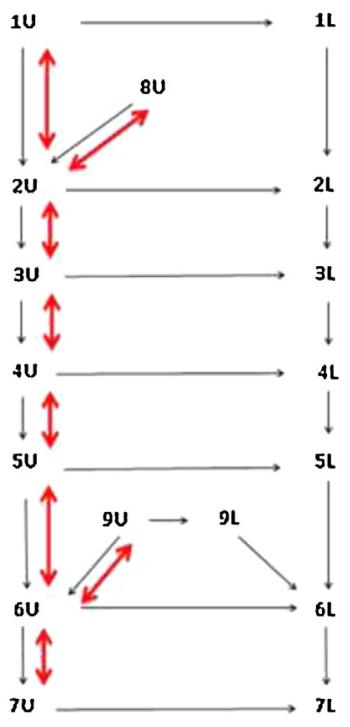

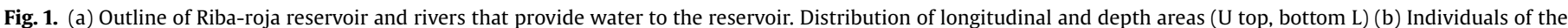

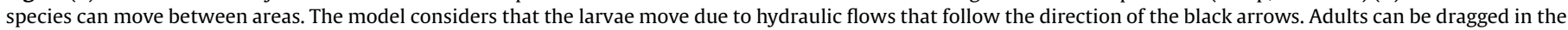

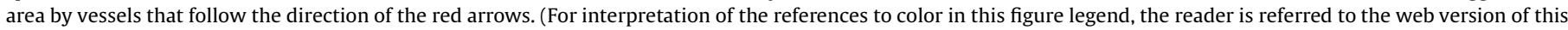
article.)

population size have been documented, with their numbers decreasing when adult zebra mussel densities are higher, with the exception of the relationship found by Strayer and Malcom (2006)".

After this stage, individuals tend to fall onto the substrate due to their increase in weight and the force of gravity, and they settle there if conditions are favorable.

Mortality between the spawning period and the beginning of the juvenile stage can be as high as $98 \%$. However, given that females can produce between 40.000 and 1.000 .000 eggs (O'Neill, 1996), the natural population growth rate remains very high despite the high mortality.

Two different annual reproductive periods are usually observed in the reservoir of Riba-roja: the first from late March to June, and the second from mid-October to early November, coinciding with those observed in other reservoirs in the Northern Hemisphere (Sprung, 1993; Borcherding, 1991). The most important period is the first, where an estimated $80 \%$ of eggs are released by females. Meanwhile, in the second period young individuals can reach sexual maturity. Larvae production is underactive when the water temperature is between 12 and $15^{\circ} \mathrm{C}$, becoming slightly higher when it is between 15 and $17^{\circ} \mathrm{C}$ (Jenner et al., 1998).

Larvae move vertically to deeper zones by the effect of gravity, horizontally due to wind, or following the flow of water, thus able to settle into other areas. The movement of larvae, along with the activation of the reproductive period depending on the water temperature distribution, causes a great desynchronization in the life cycle of the species, such that individuals can be found in various stages of development at the same place and time.

Whereas larvae falling onto sandy or silty substrates cannot survive, those falling onto rocky or harder substrates can. The movements of the young mussels are negligible under natural conditions (Ackerman and Claudi, 1991), but they can be affected by displacements caused by floating elements such as boats, logs or other human interventions.

Mussel growth is related to the water temperature, registered since its binding onto the substrate. This growth is optimal between 18 and $20^{\circ} \mathrm{C}$, gradually decreasing outside this interval.
The time needed for individuals to reach sexual maturity depends on the water temperature.

Zebra mussels can form dense aggregations of individuals arranged in several layers, one above the other. Maximum densities above 100.000 individuals per $\mathrm{m}^{2}$ have been observed in Ireland (Minchin et al., 2005), while up to 250.000 individuals per $\mathrm{m}^{2}$ have been found in the Riba-roja reservoir (Palau et al., 2003).

\subsection{The study area}

In this study, the population dynamics of zebra mussels are modelled in the reservoir of Riba-roja, located in northeastern Spain (Fig. 1a). The reservoir is $35 \mathrm{~km}$ long, and the depth varies, reaching up to $28 \mathrm{~m}$ deep. It receives water from the Ebro, Segre and Matarraña rivers, although the latter provides only a small quantity of water and has not been taken into account in the model, although it is sufficient to transport larvae. As a preliminary approach, this reservoir presents a hydrodynamic organization (Navarro et al., 2006) with a stratification of the water column due to the interaction between colder and more mineralized water from the Ebro River located at the bottom, and less mineralized, warmer water, with a greater concentration of nutrients, coming from the Segre River, flowing near or through the surface. This arrangement allows the distinction of two clearly different layers in the water column in the reservoir throughout the year (upper, $U$, and lower, L), especially in summer, when the incoming waters from Segre are warmer.

Given the large size of the reservoir, its thermal conditions and the nature of the substrate cannot be considered homogeneous (Dolz and Armengol, 2009), so it is necessary to divide the reservoir both by depth and longitudinally. Previous works have concluded that 9 different zones can be distinguished longitudinally, each of them divided by depth into two parts, for a total of 17 areas (Fig. 1), as a consequence of the Segre river depth (Table S5). The life cycle of the zebra mussel may develop at different rates and with different intensity in each area. 


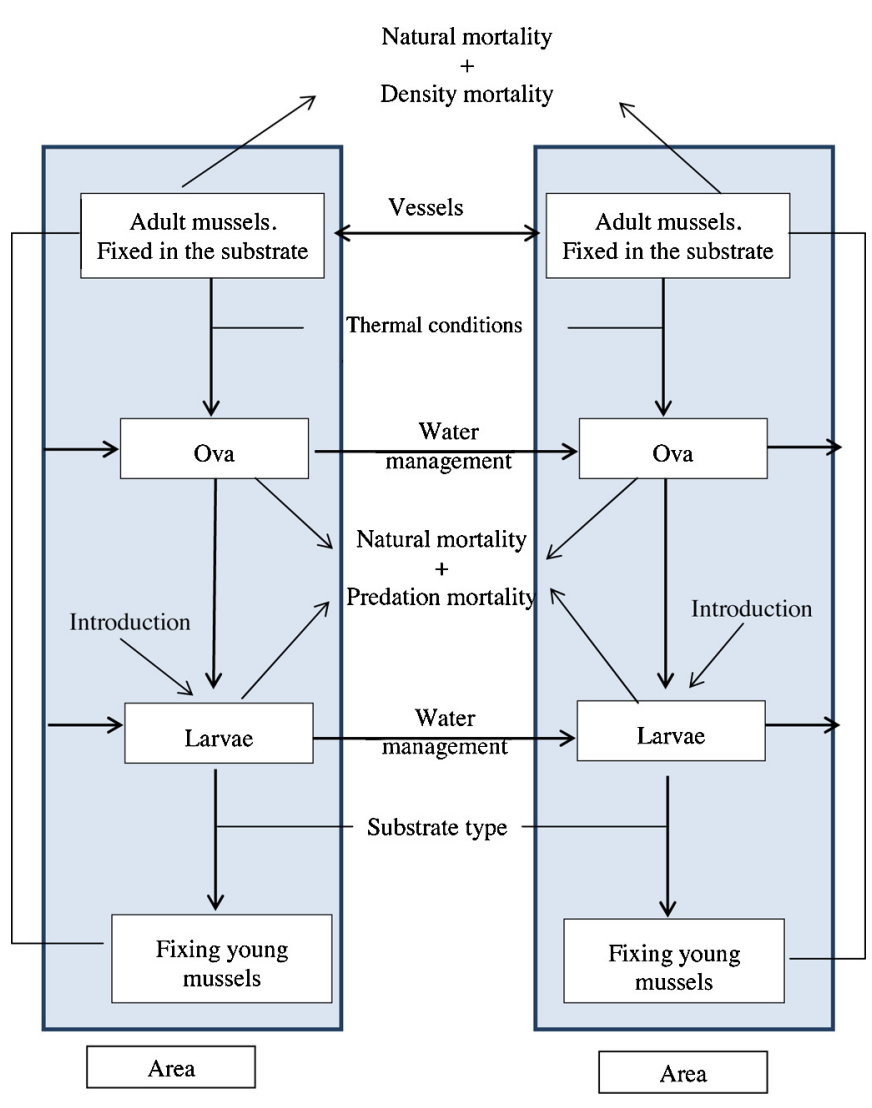

Fig. 2. Biological processes that are carried out in two adjacent compartments of the reservoir and environmental variables affecting the processes.

\subsection{The population dynamic P-system (PDP) model to study the dynamics of the zebra mussel}

The ecosystem to be modeled is very complex as a consequence of the combined effect of different features: the biological cycle of zebra mussels, the heterogeneity of the physical environment, the size of the reservoir, and its water turnover. Thus, the variations in the level of water can be considered negligible. As a result, the application of conventional techniques for modelling may be unfeasible, making it necessary to use more powerful models such as the computational models based on PDP systems (Colomer et al., 2013).

In order to study the population dynamics of the zebra mussel in the reservoir of Riba-roja, a number of factors have been considered: (1) The basic biological processes of the species, determined by the thermal conditions and the substrate suitability in the reservoir; (2) The features of the special habitat under study, that is, an artificial reservoir with water currents and eddies, and changes in water renewal depending on the depth and time of year, according to the reservoir management for hydropower and characteristics of incoming water; (3) The possibility of external larvae entering from an upstream reservoir and the transfer of individuals to the reservoir by boats.

The thermal conditions of the water inside each of the 17 zones will determine the start and duration of the biological cycle. The nature of the substrate will affect the density of mussels and therefore the mortality of larvae (Table S4).

When a thermal threshold is reached inside an area, individuals start reproducing progressively as they reach sexual maturity (Table S3). Young individuals reaching sexual maturity later, if thermal conditions remain suitable, will also start releasing eggs.
As a consequence, every area can concurrently contain individuals at different reproductive stages evolving simultaneously. Along with this desynchronization, and characteristics of the biology of the species, another factor must be considered in this study: the effect of human actions on water dynamics, able to move larvae between areas or even outside the reservoir (Fig. 1b).

With the aim of describing the model in a systematic way, the steps of the protocol proposed in Colomer et al. (2013) will be followed. As consequence of the complexity of the model, the number of variables introduced are important. For this reason, when some parameters are not available for the study area, we used values obtained from the literature under that have been checked by the experts responsible of the monitoring of the species in the reservoir. In this sense, the main advantage of PDP models is that the updating of parameters introduced can be modified without affecting the model.

\section{Stage 1 Objective}

Modelling the population dynamics of the zebra mussel in the Riba-roja reservoir, to develop a tool to measure the effectiveness of possible control actions on the larvae population in the reservoir. The output of the model will be the distribution of larvae and the number of adult individuals throughout the year.

Stage 2 Modelling processes

Different biological and environmental processes, as well as those managed by humans, will be modeled, all of them interacting with each other.

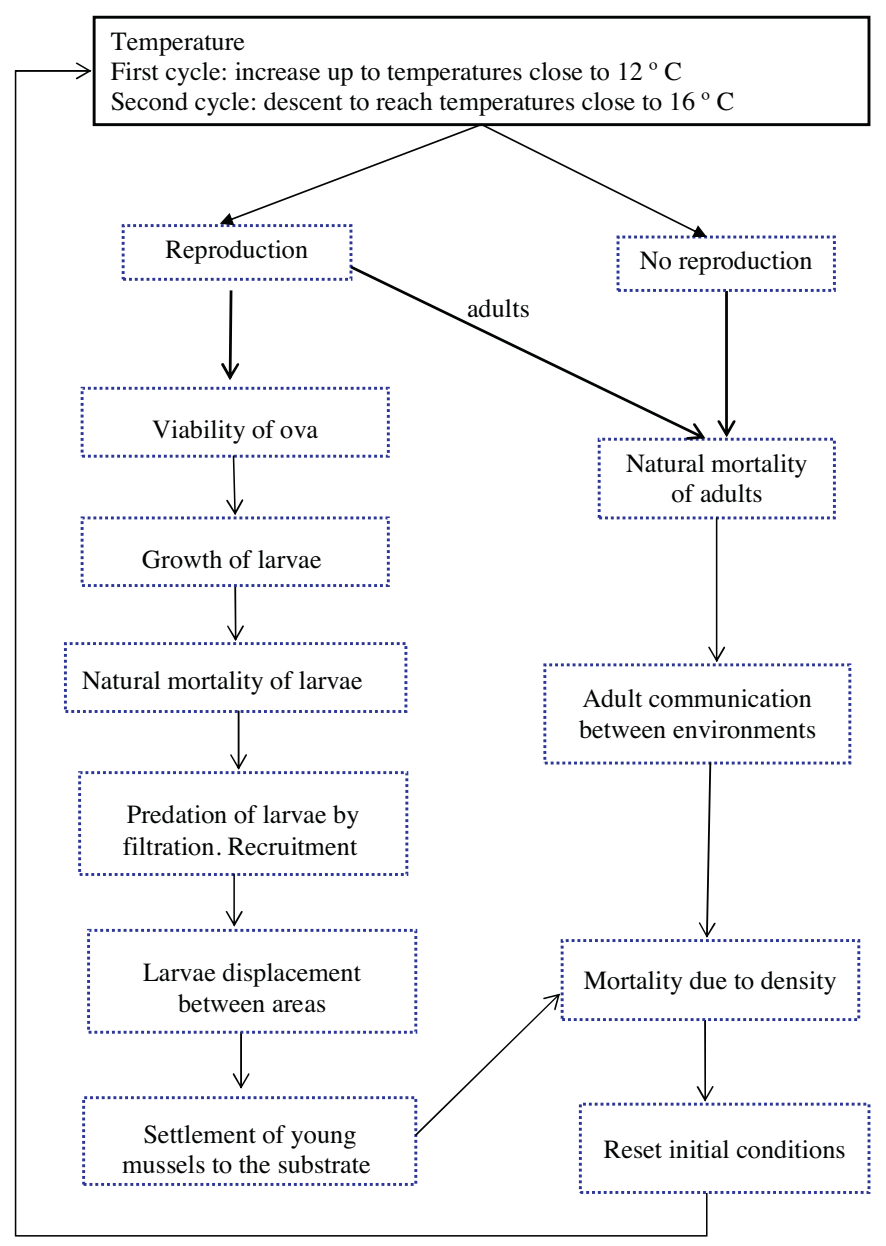

Fig. 3. Schematic model. Partial sequencing processes running individual mussels. Each specimen may initiate the loop at different times. The processes sequenced in the figure are parallel and running in an area at the same time. The processes are out of sync between areas. The passage of a year represents running the loop twice. 
- Biological processes: release of eggs, larval stage, binding to the substrate, mortality at different stages and depredation (filtering of larvae and eggs by adult individuals).

- Environmental processes: random generation of thermal conditions and control of the carrying capacity depending on the substrate suitability present in every area of the reservoir.

- Processes managed by humans: shift of larvae among areas, caused by water management to generate hydroelectric power, external introduction of larvae and displacement of adult individuals due to boat movements.

Fig. 2 shows a diagram including the different processes and interactions involving two different areas. The complexity of the full model is obviously greater, given the 17 existing areas that are communicating with each other. The processes being modelled occur simultaneously within and among the zones.

Stage 3 Input of the model and parameters to be taken into account

The input of the model is the initial population size and the parameters of the model are shown in Supplementary information (Tables S1-S6). Because information for all parameters necessary for the model is not available from Riba-roja reservoir, we used several variables obtained from other areas, but validated by researchers working in our study area. There are some parameters representing data about the nature of the reservoir and the physical environment, such as size (dimensions), type of substrate and thermal conditions. Some depend on the management of the reservoir, where human interaction takes place (water flows, movement of vessels and external introduction of larvae).

Stage 4 Sequencing and parallelization of the processes

It would be extremely complex to fully sequence the problem being modeled, so a partial sequencing of the processes is proposed (Fig. 3). The initial processes will be enabled as soon as a temperature threshold is reached, triggering the start of the reproduction phase. The duration of this process will depend on the cycle. Once the egg release has begun, the model will be desynchronized, with different processes taking place at the same time: egg release, movement of larvae of different ages, and binding to the substrate of individuals in a more advanced stage of development, depending on the existing population and the kind of substrate. In addition, some adult individuals may also experience movements due to vessel traffic. The presence of young individuals, reaching sexual maturity later than adults, increases the difficulty of sequencing these processes.

The model will be synchronized by applying a process of density-dependent mortality. The last module of the loop will permit the restoration of the initial configuration and prepare the model for the beginning of the next cycle. It is necessary to run the loop in Fig. 3 twice in order to cover the course of a year.

In order to simplify the movement of the hydraulic flow in the reservoir, a turbulent flow is considered (Reynolds number $=36$ $\times 10^{6}$ ), taking the approximate speeds from Dolz and Armengol (2009). The cross section of the reservoir is divided into seven parts where the input flow is distributed, adopting the different water speeds depending on the incoming flow. A new algorithm has been designed to estimate the final distribution of water inside each area on a weekly basis, thus influencing the probability of larvae movement among areas.

Stage 5 Designing of the model

The main components of a PDP model are:

- Number of environments

- Membrane structure

- Initial alphabet

- Evolution rules
An environment will be associated with each one of the 17 areas in the reservoir. The cell inside each environment will contain 40 membranes, 39 internal membranes and the skin membrane labeled with the value 0 . Therefore, the membrane structure of each $P$ system is as follows:

$\mu=\left[[]_{1} \cdots[]_{36}[]_{37}[]_{38}[]_{39}\right]_{0}$

The first 20 membranes will be associated with the 20 weeks for which the first reproductive cycle can last. Similarly, the next 16 will be associated with the weeks of the second reproductive cycle. Membranes 37 and 38 will be used to perform the process related to mortality, depending on the density of mussels. Membrane 39 is related to the process of recruitment of larvae, which depends on the population size.

The initial configuration of the model (i.e., input objects) is the following:

$M_{0}=\left\{X_{i}^{q_{k i}}, Q_{d}^{q_{k d}}\right\}, 1 \leq k \leq E, 2 \leq i \leq 6,1 \leq d \leq 52$.

$M_{j}=\{\alpha\}, 37 \leq j \leq 39$.

$M_{e_{j}}=\left(T_{0}, I_{1}\right), 1 \leq e_{j} \leq 17$

Each mussel is associated with an object $X_{i}, i$ being the age in semesters. The number of mussels with age $i$ initially placed in the environment $k$ is $q_{k i}$. Similarly, $Q_{d}$ are objects representing mussels younger than 1-year old, d being the age in weeks; $q_{k d}$ is the total number of mussels aged d weeks inside environment $k$.

Object $\alpha$ is used to enable and synchronize processes taking place inside membranes 37,38 and 39 . Object $I_{1}$ permits the external introduction of larvae.

The model is initialized by applying the process of random generation of temperatures through the object $T_{0}$ placed in the environment.

The proposed model involves a main loop whose body is composed of several modules (Fig. 3). Each iteration of the loop starts by running the temperature module. The model includes 150 types of rules (116 skeleton rules, internal to the P system of the cell, and 34 environment rules). Once the rule types (patterns) are unfolded, they imply a total of 144.610 specific rules Following the scheme proposed in stage 4 , we will express mathematically the evolution rules (types of rules) for the processes involved in each module that appear detailed in the Supplementary information.

To summarize, the model evolution begins by randomly generating the temperature of the water for each environment. As soon as favorable conditions for reproduction are present the corresponding rules are initiated, in such a way that each object representing a female $X_{i}$ at reproductive age generates new objects $\mathrm{O}_{\mathrm{m}}$ for released eggs, whose number depends on the age of the reproductive animal. The index of the object saves information related to its age, given that the release of these ovules expands over time. Some eggs are not viable and dissolve. The remaining objects $\mathrm{O}_{\mathrm{m}}$ evolve to objects $\mathrm{L} 1_{\mathrm{m}}$ representing larvae whose ovules were released during week $\mathrm{m}$. After one week, objects $\mathrm{L} 1_{\mathrm{m}}$ evolve to $\mathrm{L} 2 \mathrm{~m}$, then to $\mathrm{L} 3_{\mathrm{m}}$ and finally after 4 weeks to objects $\mathrm{L}_{\mathrm{m}}$. For those 4 weeks, larvae are present in the water column, such that the water movement may cause them to shift from one environment to another during this larval stage. Rules related to the change of environment are applied at the end of the larval stage. The process of settlement is then initiated. Its success will depend on the substrate type and the density of previously settled mussels. If this 
Table 1

Hydraulic renewal scenarios studied $\left(\mathrm{m}^{3} / \mathrm{s}\right)$ in the Riba-roja reservoir.

\begin{tabular}{|c|c|c|c|c|c|c|c|c|c|c|c|c|c|}
\hline Week & Data & $\begin{array}{l}\text { Scenario } \\
1\end{array}$ & $\begin{array}{l}\text { Scenario } \\
2\end{array}$ & $\begin{array}{l}\text { Scenario } \\
3\end{array}$ & $\begin{array}{l}\text { Scenario } \\
4\end{array}$ & $\begin{array}{l}\text { Scenario } \\
5\end{array}$ & $\begin{array}{l}\text { Scenario } \\
6\end{array}$ & $\begin{array}{l}\text { Scenario } \\
7\end{array}$ & $\begin{array}{l}\text { Scenario } \\
8\end{array}$ & $\begin{array}{l}\text { Scenario } \\
9\end{array}$ & $\begin{array}{l}\text { Scenario } \\
10\end{array}$ & $\begin{array}{l}\text { Scenario } \\
11\end{array}$ & $\begin{array}{l}\text { Scenario } \\
12\end{array}$ \\
\hline 5 & 29 March-4 April & 150 & 300 & 325 & 350 & 0 & 0 & 0 & 0 & 0 & 0 & 0 & 0 \\
\hline 6 & 5-11 April & 150 & 300 & 325 & 350 & 0 & 0 & 0 & 0 & 0 & 0 & 0 & 0 \\
\hline 7 & 12-18 April & 150 & 300 & 325 & 350 & 0 & 0 & 0 & 0 & 0 & 0 & 0 & 0 \\
\hline 8 & 19-24 April & 150 & 300 & 325 & 350 & 0 & 0 & 0 & 0 & 0 & 0 & 0 & 0 \\
\hline $9-12$ & 25 April-22 May & 150 & 300 & 325 & 350 & 325 & 325 & 325 & 325 & 325 & 325 & 325 & 325 \\
\hline 13 & 23-29 May & 150 & 300 & 325 & 350 & 325 & 325 & 325 & 325 & 325 & 0 & 0 & 0 \\
\hline $14-18$ & 30 May-3 July & 150 & 300 & 325 & 350 & 325 & 325 & 325 & 325 & 325 & 325 & 325 & 325 \\
\hline 19 & 4-10 July & 150 & 300 & 325 & 350 & 325 & 325 & 325 & 325 & 325 & 0 & 325 & 325 \\
\hline 20 & 11-17 July & 150 & 300 & 325 & 350 & 325 & 325 & 325 & 325 & 325 & 325 & 325 & 325 \\
\hline 21 & 18-24July & 150 & 300 & 325 & 350 & 325 & 325 & 0 & 0 & 325 & 325 & 325 & 325 \\
\hline 22 & 25-31 July & 150 & 300 & 325 & 350 & 0 & 0 & 0 & 0 & 0 & 0 & 0 & 0 \\
\hline 23 & 1-7 August & 150 & 300 & 325 & 350 & 0 & 0 & 0 & 0 & 0 & 0 & 0 & 0 \\
\hline 24 & 8-14 August & 150 & 300 & 325 & 350 & 325 & 0 & 325 & 0 & 0 & 325 & 325 & 0 \\
\hline $25-27$ & $\begin{array}{l}15 \text { August- } \\
4 \text { September }\end{array}$ & 150 & 300 & 325 & 350 & 325 & 325 & 325 & 325 & 325 & 325 & 325 & 325 \\
\hline 28 & 5-11 September & 150 & 300 & 325 & 350 & 325 & 325 & 325 & 325 & 325 & 0 & 0 & 0 \\
\hline $29-33$ & $\begin{array}{l}12 \text { September- } \\
16 \text { October }\end{array}$ & 150 & 300 & 325 & 350 & 325 & 325 & 325 & 325 & 325 & 325 & 325 & 325 \\
\hline 34 & 17-23 October & 150 & 300 & 325 & 350 & 325 & 325 & 325 & 325 & 325 & 0 & 325 & 325 \\
\hline 35 & 24-30 October & 150 & 300 & 325 & 350 & 325 & 325 & 325 & 325 & 325 & 0 & 325 & 325 \\
\hline $36-38$ & $\begin{array}{l}31 \text { October- } \\
20 \text { Novemeber }\end{array}$ & 150 & 300 & 325 & 350 & 325 & 325 & 325 & 325 & 325 & 325 & 325 & 325 \\
\hline
\end{tabular}

process finishes successfully for the larva, it evolves to an object $\mathrm{Q}_{\mathrm{m}}$ ( $m$ being its age in weeks). At 54 weeks old, object $\mathrm{Q}_{\mathrm{m}}$ evolves to $X_{i}$, with index $\mathrm{i}$ representing its age in semesters. During the final stage of settlement, objects associated with mussels undergo different steps of evolution, given that above a certain density some of the new individuals will die; moreover, the probability of dying increases according to the age of the mussel. Simultaneously to the previously described processes, two other processes take place: human reintroduction of larvae in different compartments along the reservoir, and movement of adult individuals due to the navigation of vessels. For the first process, some rules generate objects $\mathrm{O}_{\mathrm{m}}$ following the later processes described above. The second is performed by an environment rule implying the displacement of some adult individuals among different compartments.

Stage 6 Defining a simulator to run the model

Once the model is defined, the next step is to define a simulator that allows the model to be run efficiently. A software tool allowing the management of the model to predict the dynamics of zebra mussels is needed in order to facilitate the management decisions of the reservoir. MeCoSim (Pérez-Hurtado et al., 2010, http://www. p-lingua.org/mecosim) was used to design the simulator interface. Input values (i.e., parameters and value variables of the model) are introduced directly into the interface of the simulator. In order to study the behaviour of the model in a specific scenario, we simply need to change the input values in this interface.

\subsection{Scenarios under study}

The aim of modelling the population of zebra mussels in the reservoir of Riba-roja is to provide a management tool to aid in the decision-making process, with the aim of eradicating or decreasing the population of these invasive mussels.

Three different scenarios have been studied:

1. The first set of simulations is addressed to determine the effect of the current water flow on the reservoir. Two different scenarios have been simulated: the first is a controlled scenario without water flows, while the second reflects the current regime (Table S6).

2. The goal of the second set of simulations is to obtain a water flow (water turnover) that allows the elimination of the zebra mussel in the reservoir, keeping the other conditions constant. The studied scenarios are shown in Table 1. The proposed times for inducing hydraulic flows were chosen taking into account the distribution of larvae observed in the controlled scenario. These hydraulic flows were $150,300,325$ and $350 \mathrm{~m}^{3} / \mathrm{s}$, remaining constant over time and the same for both the upper lower areas. This study is focused on the reservoir areas where greater amounts of mussels are present.

3. The last set of simulations aimed to test one of the main hypotheses concerning the invasion of the zebra mussels in the reservoir. It studies the effect of the external introduction of larvae considering the current hydrological regime (Table S6).

\subsection{Statistical analyses}

In order to determine whether there are significant differences in the population dynamics of zebra mussels under the scenarios considering the management of the hydrological regime, the $t$-test has been applied on the paired data.

\section{Results}

\subsection{Effect under the current hydraulic regime}

Fig. 4 shows the differences between the population dynamics of zebra mussel larvae under the scenario with the current regime of flow renewal (Table S6) and without flow renewal (controlled scenario). Significant differences were found in practically all areas $(p<0.0001$ in all cases except in 6L, 7L, 9U and 9L, Fig. 4), such that population size decreases significantly if water flow exists. There are no statistically significant differences in the upper areas of the reservoir, which balances the new larvae that are released from the reservoir with larvae from the areas that are located upstream.

When no water flow exists, different population patterns are observed. On the one hand, cycles of 4-5 years occur in the population dynamics of some areas $(1 \mathrm{U}, 1 \mathrm{~L}, 4 \mathrm{U}, 4 \mathrm{~L}, 7 \mathrm{~L})$. On the other hand, in other areas there exists an initial demographic explosion followed by a subsequent stabilization of the population (2U, 2L, 3U, 3L, 6L, 9L).

Fig. 5 shows the distribution of larvae in the reservoir for two years (9-10 of the 30 simulated) in two different scenarios, the first 

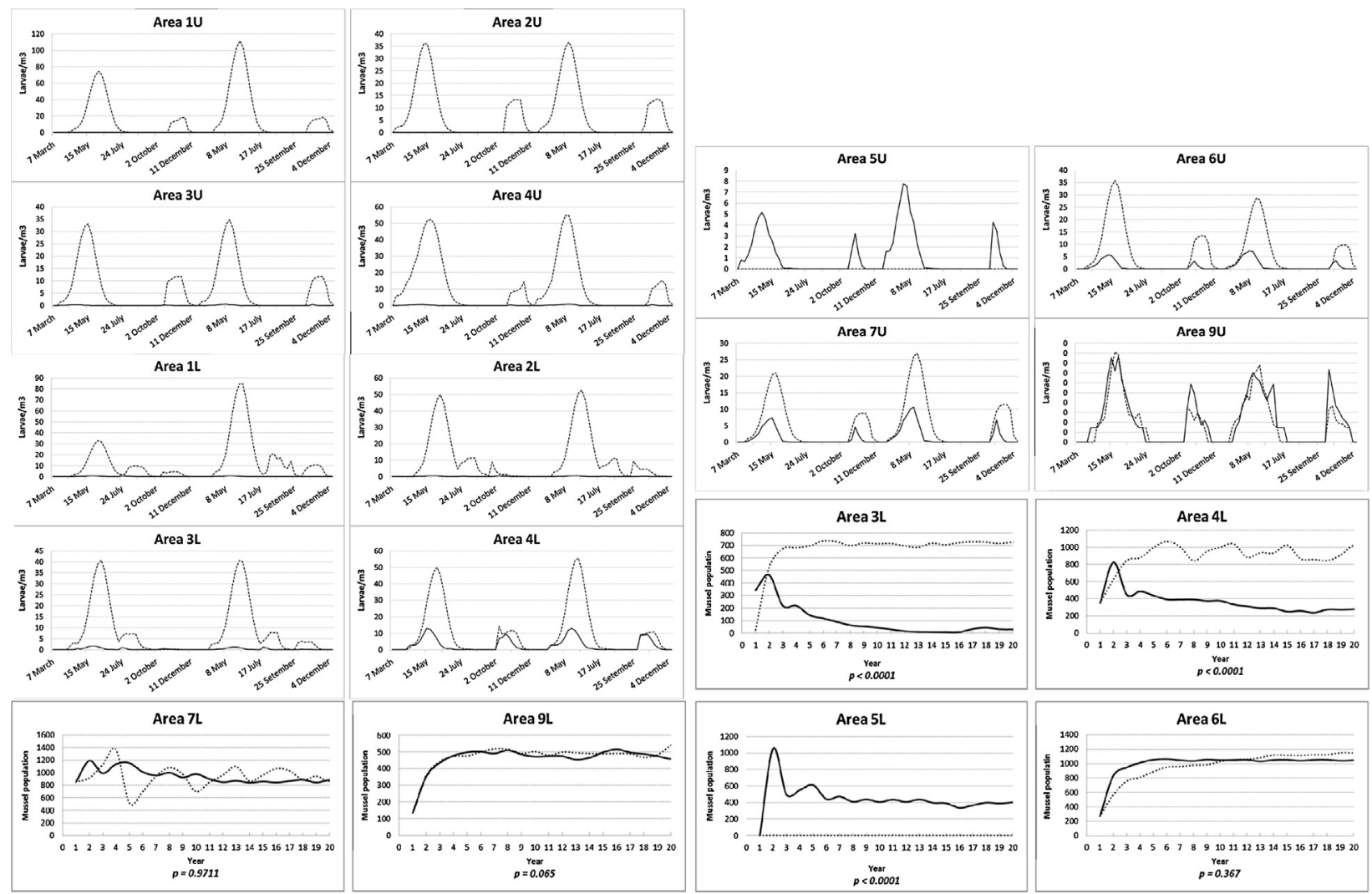

Fig. 4. Dynamics of zebra mussels in each area. Continuous line represents the current renewal regime (Table S6), the dashed line represents no renewal. Results of paired $t$ test.

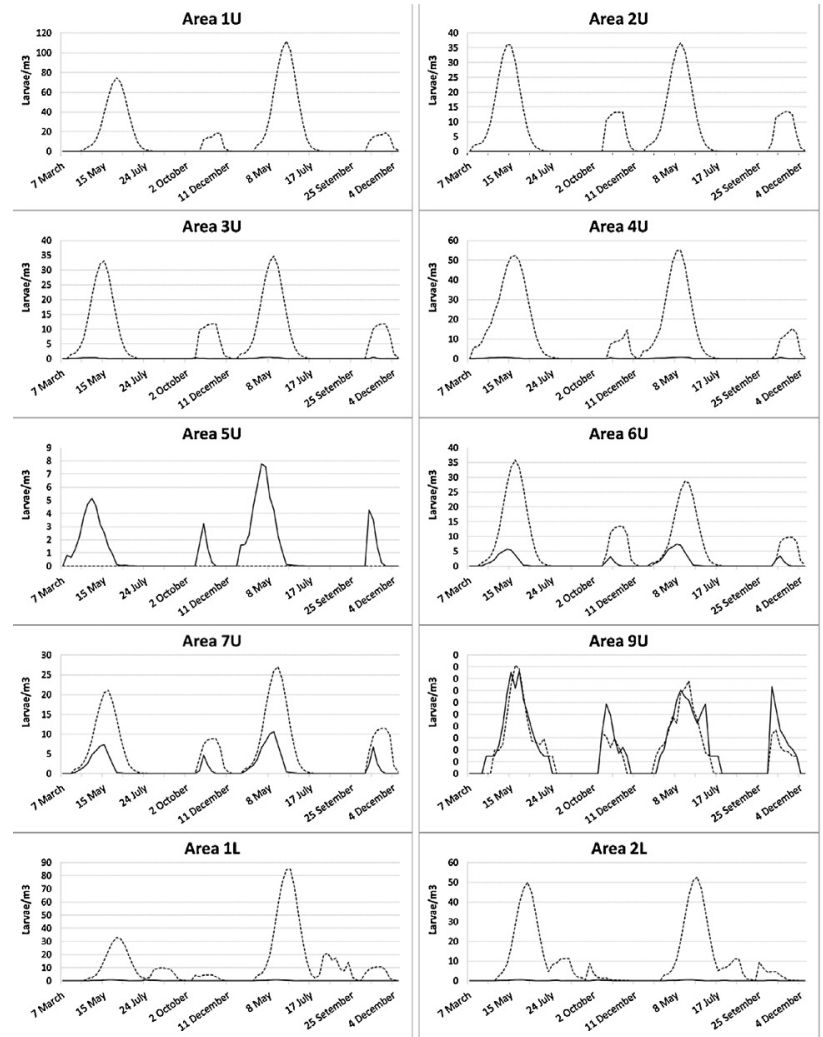

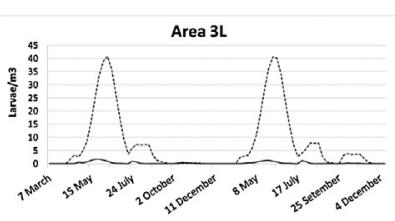
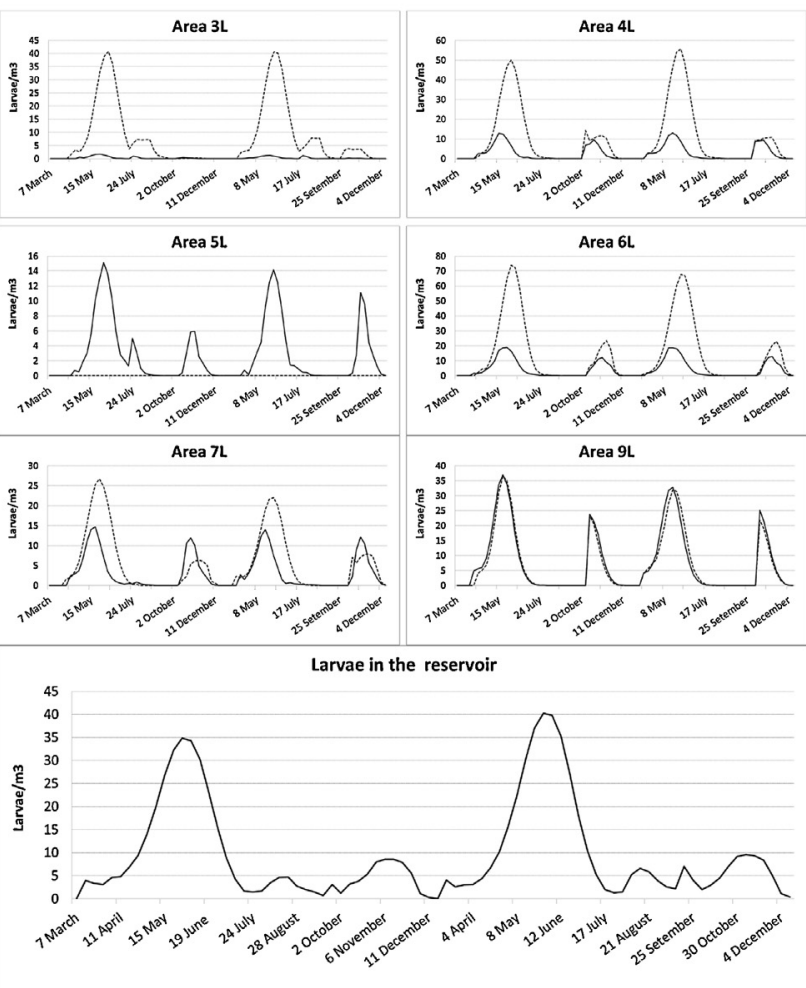

Fig. 5. Distribution of larvae in the different areas, without renewal represented by dashed line, solid line representing current flow renewal (Table S6). The distribution of larvae in the reservoir in general lacks renewal. 

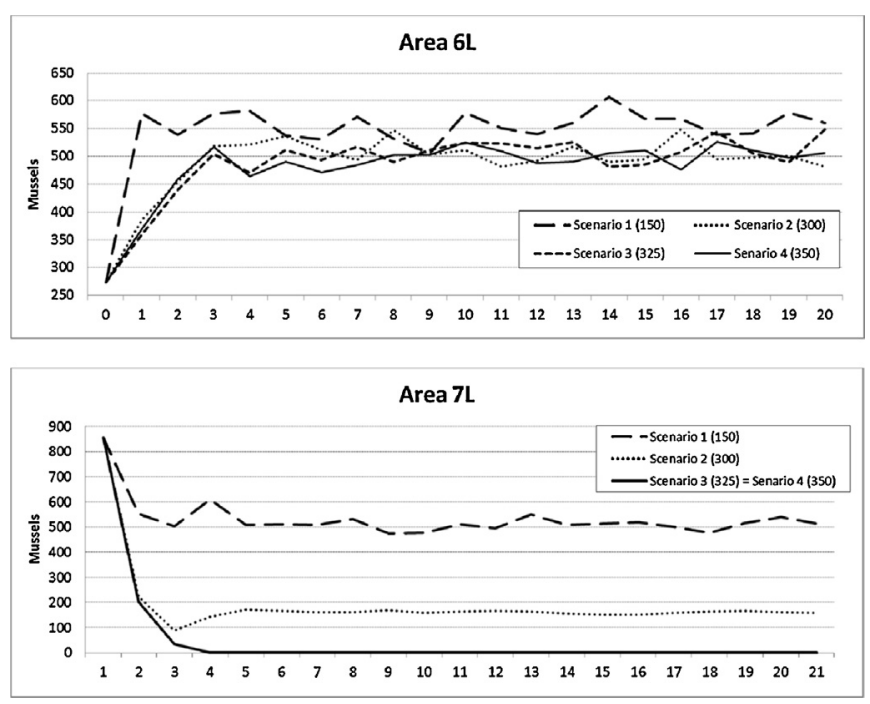

Fig. 6. Zebra mussel population distribution for different hydraulic flow scenarios

involving water flow (Table S6) and the second without it. Analyzing the results by area, a central period without larvae is observed, ranging from 2 to 5 weeks depending on the thermal conditions. This period does not occur at the same time in all areas. Moreover, it can be observed that larvae exist at all times in some of the areas (Fig. 5).

As shown in Fig. 5, as we approach the outlet a decrease in the differences between both scenarios is observed, although they continue to be statistically significant $(p<0.05)$. The differences are more important upstream, which is reasonable if taking into account the comparison of adult specimens previously made. No significant differences exist in lateral rivers (9U and 9L) supplying water to the reservoir, where the distribution of larvae is practically the same independent of the presence of water flow.

\subsection{Population dynamics of adults under different scenarios involving hydraulic regimes}

Scenarios 1, 2, 3 and 4 (Table 1) have been studied, applying the water flows at the same time but varying the amount of water (150, 300,325 and $350 \mathrm{~m}^{3} / \mathrm{s}$, respectively). It is observed that in the less favorable area, the header area $7 \mathrm{~L}$, the removal of the species is achieved by applying flows of $325 \mathrm{~m}^{3} / \mathrm{s}$ for 4 years (Fig. 6).

In the pre-header area $(6 \mathrm{~L})$, it was not possible to eliminate the species by applying the tested flows. With values greater or equal to $300 \mathrm{~m}^{3} / \mathrm{s}$ the population stabilizes at approximately

\section{Area $6 \mathrm{~L}$. Scenario 3}

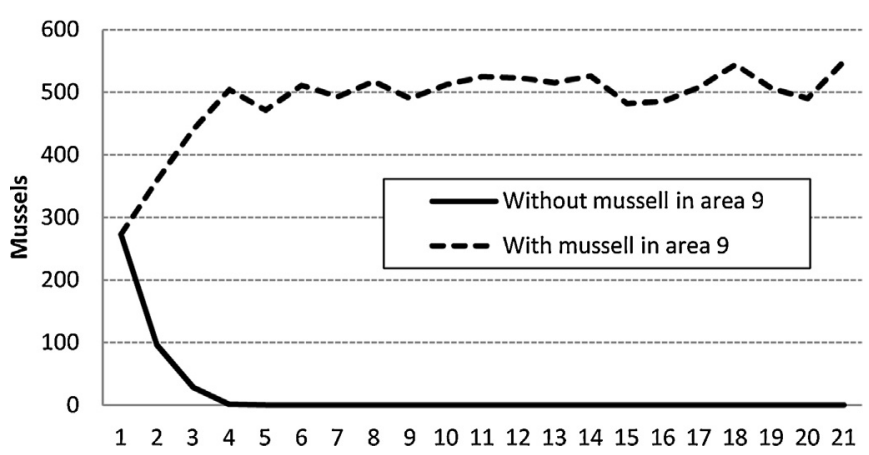

Fig. 7. Distribution of the zebra mussel population in area $6 \mathrm{~L}$ depending on whether or not there are mussels in area 9.
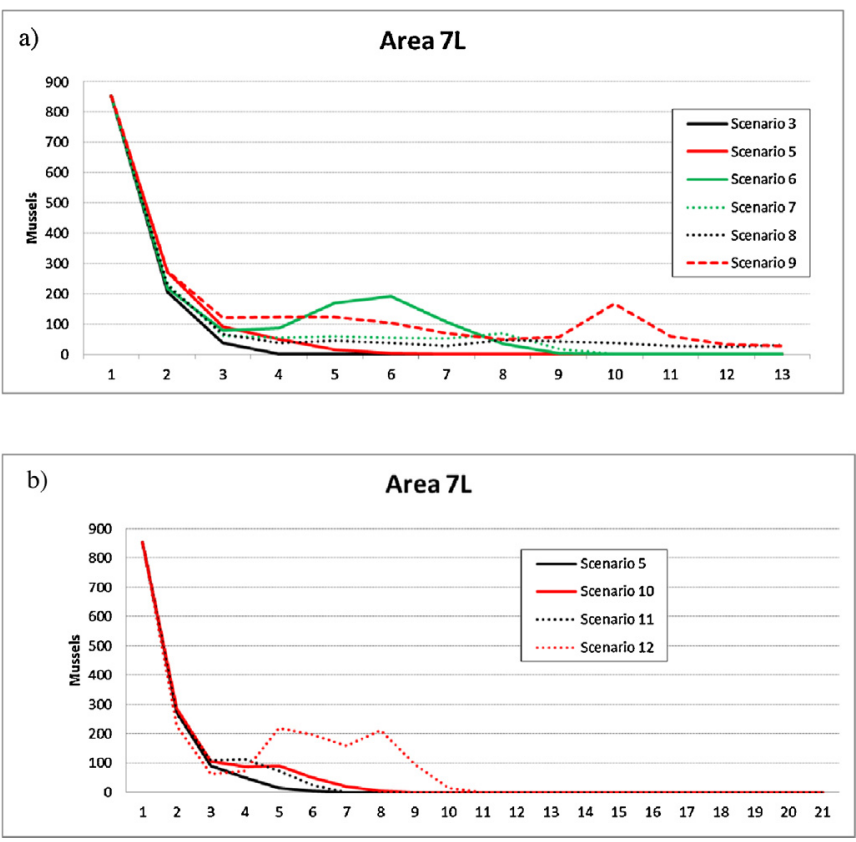

Fig. 8. Distribution of the zebra mussel population in area $7 \mathrm{~L}$ for different scenarios, (a) removing hydraulic flow in the central period between reproductive cycles of the species, (b), suppressing the hydraulic flow between the species' reproductive cycles and within the cycle.

500 individuals as a consequence of the supply of larvae from Matarraña River: young larvae are carried by water flow out of the reservoir, previously passing through areas $6 \mathrm{~L}$ and 7L; larvae of 26-28 days moving from Matarraña River to area 6L fix to the substrate, thereby preventing the eradication of the species in this space.

Fig. 7 shows the population dynamics in area 6L in different scenarios with the presence or absence of the species in Matarraña River. In the case of absence, the population would be extinguished in a period of four years with a hydraulic flow of $325 \mathrm{~m}^{3} / \mathrm{s}$.

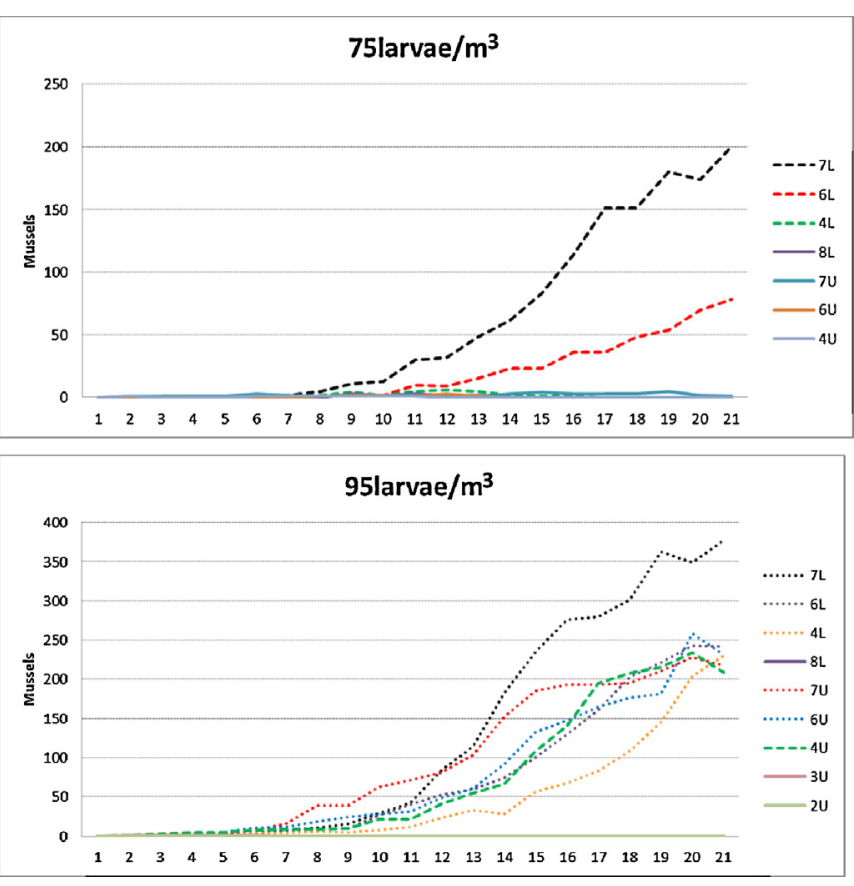

Fig. 9. Mussel colonization simulation according to introduced larvae. 
However, if no action is taken to control the species in Matarraña River, this affluent acts as a reservoir.

Taking as a starting point water flow of $325 \mathrm{~m}^{3} / \mathrm{s}$ from late March to mid-November, the effect of delaying or not applying water movement in the reservoir for a few weeks was studied (Table 1). If the water flow starts in late April, for two weeks during the time with less larval activity without water movements in the reservoir (scenario 5), it is estimated that the species would be removed from the reservoir after 5 years (Fig. 8). If the period of low larval activity is increased with an additional week without water movement (scenarios 6 and 7), an estimated time of 9 years is needed to extinguish the species. If this period continues to increase (scenarios 8 and 9), a reduction in the population size is observed, but does not imply the eradication of the species.

Removing the water flow for some weeks during the larval period (scenarios 10,11 and 12) leads to a delay in the eradication of the species (Fig. 8).

\subsection{Effect of the reintroduction of larvae to the reservoir, previously} free of zebra mussels

The reintroduction of larvae in area $7 \mathrm{U}$ in amounts above 75 larvae $/ \mathrm{m}^{3}$ can cause the settlement of the species in the reservoir, reaching the header area $7 \mathrm{~L}$ in densities of 200 adult mussels $/ \mathrm{m}^{2}$ after 20 years (Fig. 9). Practically no mussels stay fixed in the upper areas given this amount of individuals. If the introduction rises to 95 larvae $/ \mathrm{m}^{3}$ then more areas are colonized, achieving larger populations and causing the settlement of mussels in the upper areas (Fig. 9). The colonization takes place mainly through transfer by recreational vessels.

\subsection{Effect of the variation of biological parameters on population size}

To study the sensitivity of the model, we executed the model varying \pm 1 the value of biological parameters modelling the effect on the population size after 20 years. Because the sensitivity of a parameter depends on the values adopted by other parameters (Table 2), the extrapolation of the values obtained must be made with caution. Larval mortality is the parameter with the most influence on the population dynamics (Table 2 ).

\section{Discussion}

The adaptive flexibility of population dynamic P-systems (PDP) shows that they may be suitable for modelling complex fluvial ecosystems in which different dynamic habitats and variables interact simultaneously. This complex scenario is impossible to model with other computational approaches such as population viability models or multi-agent systems that are currently used for the study of population dynamics. The multi-agent systems require the sequencing of processes, an aspect impossible to apply in the case study. On the other hand, the PDP models as most computer models have a strong points such as: flexibility to incorporate properties of complex systems, ability to reproduce complex emergent phenomena and virtual laboratory for understanding and evaluating performance of complex systems. Their weak points are: difficulties for calibration and validation, identification and formalization of the multiple components and interactions of a complex system and difficulty communicating the structure and functioning of the model.

Our results show that PDP models can be very useful tools to model complex, partially desynchronized, processes that work in a parallel manner. This allows the study of complex hydroecological processes such as the one presented, where reproductive cycles, temperature and water dynamics are involved in the desynchronization of the population dynamics, both within areas and among them. On the other hand, the definition of a PDP model is not simple or complex when modeling a complex system, requiring the broad experience and knowledge of the modeler at a biological level about the phenomena under study. If the inherent complexity of the problem includes many individuals whose evolutionary details must be recorded, the computational costs greatly increases, and thus more resources are necessary in terms of memory The model reveals the existence of cycles of population growth and decline with a periodicity of 4-5 years when no hydraulic flow takes place. Probably after a boom-bust cycle, a population behaviour pattern described by different authors (Stancykowska, 1977; Burla and Ribi, 1998; Petrie and Knapton, 1999; Strayer et al., 2010), population dynamics can follow different possible long-term trajectories (Strayer and Malcom, 2006). According to our results, a cyclic pattern seems to be the most plausible behaviour for the population of zebra mussels studied. However, when water flow varies, some stabilization and decrease patterns are observed (Strayer and Malcom, 2006).

Taking into account the current flow renewal system in the reservoir, it is observed that the population of zebra mussels remains, with population cycles fitting well with those described in the literature (Stancykowska, 1977; Strayer et al., 2010). With the current system to renew the hydric regime, some significant differences are observed regarding the no existence of flow renewal, in practically all the areas except 6L, 7L, 9U and 9L (Figure 4 ), in such a way that the population size decreases if water flow is present. The only exception occurs in area 5 (5U and 5L), where settlement occurs as a consequence of the displacement of larvae from the other areas due to the water flow present in the reservoir. This process also occurs when no flow renewal takes places, suggesting that the results obtained from the model are reliable enough in relation to an ecosystem in which a zebra mussel population is present.

The periodicity in the population variations becomes more evident when human action is involved, in this case by altering the water flow, implying important changes in the hydric flow in the area under study. The presence of this kind of cycle in the

Table 2

Variation in the size of the population by increasing the value of the parameter by $1 \%$.

\begin{tabular}{|c|c|c|c|c|}
\hline Compartment & Percentage of eggs emitted in the first cycle & Egg reduction & Larvae mortality & Adult mortality \\
\hline L4 & $0.90 \%$ & $9.76 \%$ & $-116.33 \%$ & $-6.67 \%$ \\
\hline L5 & $4.96 \%$ & $7.99 \%$ & $-68.83 \%$ & $3.09 \%$ \\
\hline L6 & $7.39 \%$ & $8.59 \%$ & $-60.34 \%$ & $2.16 \%$ \\
\hline L7 & $4.47 \%$ & $7.62 \%$ & $-56.47 \%$ & $-3.26 \%$ \\
\hline $\mathrm{U} 4$ & $-8.59 \%$ & $0.21 \%$ & $-80.43 \%$ & $4.45 \%$ \\
\hline U5 & $-8.01 \%$ & $4.59 \%$ & $-68.27 \%$ & $3.06 \%$ \\
\hline U6 & $1.29 \%$ & $-0.16 \%$ & $-7.89 \%$ & $1.17 \%$ \\
\hline U7 & $-2.59 \%$ & $-4.25 \%$ & $-42.63 \%$ & $2.15 \%$ \\
\hline
\end{tabular}


population dynamics of zebra mussels could be explained by density-dependent effects. On the other hand, the predation of larvae by the species itself increases according to an increase in population density, thus decreasing the recruitment of juveniles.

The relation between larvae and adult individuals existing in the reservoir is not linear, though a larger number of larvae leads to higher number of adults. In this sense, in order to optimize the effectiveness of the actions to decrease or eliminate the population of zebra mussels, the need of an intervention during the larval period becomes clear. This action would limit the recruitment of individuals, thus affecting its population dynamics. The simulations of the model under different water flows suggest that the hydric fluctuations significantly influence the population dynamics. In the years with significant snowfall and high rainfall, taking place with average periodicities of $25 \%$, an important increase in water entering the reservoir occurs. This suggests that the hypothesis of an external introduction of larvae could be discarded as a cause of the introduction of zebra mussels in the reservoir, provided that there exist a water renewal regime similar to the current one. A possible invasion with larvae introduction could not be discarded in the case of a standing flow renewal regime for a period of time long enough for individuals to fix to the substrate.

Although it is not possible to study the sensitivity of the model to the variation of parameters, it can be concluded that the effect will depend on the compartment that evolves differently depending on the initial population. In all compartments, there is a decrease in population as a result of increasing the mortality of larvae and a slight variation in parameter values causes significant changes in population size. Variation in the other parameters caused population increases in some compartments and decreases in others. In addition, the magnitude of the changes in the remaining parameters can be considered negligible.

The results observed in this study suggest that the zebra mussel population expansion does not take place after a long lag phase as documented for other alien species (Crooks and Solué, 1999). The simulations performed based on the presented model confirm a rapid expansion after initial establishment. For example, the simple introduction of 75 larvae $/ \mathrm{m}^{3}$ in only one area enables the species to expand and rapidly colonize the entire reservoir. The spatial and temporal dynamics of the settlement occurs very quickly such that complete eradication is difficult to achieve. Finally, geographic expansion in this invasive species occurs very rapidly.

\subsection{Management applications}

The predictions based on the model suggest that renewals performed between 25 April and 20 November with flow rates of $325 \mathrm{~m}^{3} / \mathrm{s}$ could cause the practical eradication of the species in the reservoir. Note that this occurs in all areas, although data have been only presented for the area closest to the reservoir in which the highest density is achieved. Nevertheless, the flow renewal currently being applied may cause a reduction in the size of the population of mussels but would not achieve their total elimination. In this respect, the population in the header areas is high enough to reinforce the population throughout the reservoir. Therefore, the management of the lateral rivers (9U and 9L) supplying water to the reservoir, where the distribution of larvae is practically the same with or without hydraulic flow, seems essential to reducing the zebra mussel population in the reservoir. Although the feasibility of this approach can be complicated due to the oscillations of the water regime involved, and thus difficult to achieve, it would result in the eradication of the population of the species.

The results obtained by the simulation of the presented model under the given scenarios are consistent with those published by other authors and observed by the experts responsible for the monitoring and management of the population of zebra mussels in the reservoir of Riba-roja. However, further fieldwork for data capture and recapture in different areas of the reservoir would be useful to collect more information increasing the reliability and thoroughness in the corroboration of the model.

\section{Acknowledgements}

We thank David L. Strayer and two anonymous reviewers for their review. This study was funded by Dirección de Medio Ambiente y Desarrollo Sostenible (Endesa). A. Margalida was supported by a Ramón y Cajal research contract from the Ministry of Economy and Competitiveness (RYC-2012-11867).

\section{Appendix A. Supplementary data}

Supplementary data associated with this article can be found, in the online version, at http://dx.doi.org/10.1016/j.ecocom.2014.09.006.

\section{References}

Ackerman, J., Claudi, R., 1991. The early life history of zebra mussels: overwintering juveniles and post-settlement movements. J. Shellfish Res. 11, 217.

Ackerman, J.D., Sim, B., Nichols, S.J., Claudi, R., 1994. A review of the early life history of zebra mussels (Dreissena polymorpha): comparisons with marine bivalves. Can. J. Zool. 72, 1169-1179.

Adams, D.C., Lee, D.J., 2012. Technology adoption and mitigation of invasive species damage and risk: application to zebra mussels. J. Bioecon. 14, 21-40.

Lee, D.J., Adams, D.C., Rossi, F., 2007. Optimal management of a potential invader: the case of zebra mussels in Florida. J. Agric. Appl. Econ. 39, 69-81.

Borcherding, J., 1991. The annual reproductive cycle of the freshwater mussel Dreissena polymorpha Pallas in lakes. Oecologia 87, 208-218.

Burla, H., Ribi, G., 1998. Density variation of the zebra mussel Dreissena polymorpha in Lake Zürich, from 1976 to 1988. Aquat. Sci. 60, 145-156.

Burlakova, L.E., Karatayev, A.Y., Padilla, D.K., 2006. Changes in the distribution and abundance of Dreissena polymorpha within lakes through time. Hydrobiologia $571,133-146$.

Claudi, R., Mackie, G.L., 1994. Practical Manual for Zebra Mussel Monitoring and Control. Lewis Publishers, London.

Cardona, M., Colomer, M.A., Pérez-Jiménez, M.J., Sanuy, D., Margalida, A., 2009. Modelling ecosystems using P systems: the bearded vulture, a case of study. Lect. Notes Comput. Sci. 5391, 137-156.

Cardona, M., Colomer, M.A., Margalida, A., Pérez-Hurtado, I., Pérez-Jiménez, M.J., Sanuy, D., 2010. A P-system based model of an ecosystem of some scavenger birds. Lect. Notes Comput. Sci. 5957, 182-195.

Cassagrandi, R., Mariand, L., Gatto, M., 2007. Modelling the local dynamics of the zebra mussel. Freshwater Biol. 52, 1223-1238.

Chase, M.E., Bailey, R.C., 1999. The Ecology of the Zebra Mussel (Dreissena polymorpha) in the Lower Great Lakes of North America: I. Population Dynamics and Growth. J. Great Lakes Res. 25, 107-121.

Colomer, M.A., Margalida, A., Pérez-Jiménez, M.J., 2013. Population dynamic P system (PDP) models: a standardized protocol for describing and applying novel bio-inspired computing tools. PLoS One 8, e60698.

Colomer, M.A., Margalida, A., Sanuy, D., Pérez-Jiménez, M.J., 2011. A bio-inspired computing model as a new tool for modelling ecosystems: the avian scavengers as a case study. Ecol. Modell. 222, 33-47.

Crooks, J.A., Solué, M.E., 1999. Lag times in population explosions of invasive species: causes and implications. In: Sandlund, O.T., Schei, P.J., Viken, A. (Eds.), Invasive species and biodiversity management. Kluwer Academic Publishers, Dorchecht, pp. 103-125.

Cury, P.M., Mullon, C., Garcia, S.M., Shannon, L.J., 2005. Viability theory for an ecosystem approach to fisheries. ICES J. Mar. Sci. 62, 577-584.

Daraio, J.A., Weber, L.J., Newton, T.J., Nestler, J.M., 2010. A methodological framework for integrating computational fluid dynamics and ecological models applied to juvenile freshwater mussel dispersal in the Upper Mississippi River. Ecol. Modell. 221, 201-214.

Davis, M.A., 2009. Invasion Biology. Oxford University Press, New York.

Dolz, J., Armengol, J., 2009. Estudio de la dinámica sedimentaria y batimetría de precisión del embalse de Riba-roja. Instituto Flumen. Unpubl. Report. Confederación Hidrográfica del Ebro. Zaragoza. 112 pp.

Fisher, J., Henzinger, T.A., 2007. Executable cell biology. Nat. Biotechnol. 25, 1249-1279.

Grimm, V., Revilla, E., Berger, U., Jeltsch, F., Mooij, W.M., Railsback, S.F., Thulke, H.-H., Weiner, J., Wiegand, T., DeAngelis, D.L., 2005. Pattern-oriented modeling of agent-based complex systems: lessons from ecology. Science 310, 987-991. 
Hallstan, S., Grandin, U., Goedkoop, W., 2010. Current and modeled potential distribution of the zebra mussel (Dreissena polymorpha) in Sweden Export. Biol. Inv. 12, 285-296.

Higgins, T.M., Grennan, J.M., McCarthy, K.T., 2008. Effects of recent zebra mussel invasion on water chemistry and phytoplankton production in a small Irish lake. Aquat. Inv. 3, 14-20.

Higgins, S.N., Vander Zanden, M.P., 2010. What a difference a species makes: a metaanalysis of dreissenid mussel impacts on freshwater ecosystems. Ecol. Monogr. 80, 179-186.

Jenner, H.A., Whitehouse, J.W., Taylor, C.J.L., Khalanski, M., 1998. Cooling water management in European power stations: biology and control of fouling. Hydroécol. Appl. 10, 1-225.

Johnson, C.J., Gillingham, M.P., 2005. An evaluation of mapped species distribution models used for conservation planning. Environ. Conserv. 32, 1-12.

Karatayev, A.Y., Burlakova, L.E., Padilla, D.K., 2002. Impacts of zebra mussels on aquatic communities and their role as ecosystem engineers. In: Leppäkoski, E., Gollasch, S., Olenin, S. (Eds.), Invasive Aquatic Species of Europe - Distribution, Impacts and Management. Kluwer Academic Publishers, Dorchecht, pp. 433-446.

Lindenmayer, D.B., Burgman, M.A., Akçakaya, H.R., Lacy, R., Possingham, H., 1995. A review of the generic computer programs ALEX, RAMAS/space and VORTEX for modelling the viability of wildlife metapopulations. Ecol. Modell. 82, 161-174.

Ludyanskyi, M.L., McDonald, D., MacNeill, D., 1993. Impact of the Zebra Mussel, a bivalve invader. Bioscience 43, 533-544.

MacMahon, R.F., Tsou, J.L., 1990. Impact of European zebra mussel infestation to the electric power industry. Annual Meeting of the American Power Conference, Chicago (USA), pp. 10.

Makler-Pick, V., Gal, G., Gorfine, M., Hipsey, M., Carmel, Y., 2011. Sensitivity analysis for complex ecological models - a new approach. Environ. Modell. Software 26, 124-134.

Margalef, R. 1977. Ecología. Ed. Omega. Barcelona.

Margalida, A., Colomer, M.A., Sanuy, D., 2011. Can wild ungulate carcasses provide enough biomass to maintain avian scavenger populations? An empirical assessment using a bio-inspired computational model. PLoS One 6, e20248.

Margalida, A., Colomer, M.A., 2012. Modelling the effects of sanitary policies on European vulture conservation. Sci. Rep. 2, 753.

Minchin, D., Lucy, F., Sullivan, M., 2005. Ireland: a new frontier for the zebra mussel Dreissena polymorpha (Pallas). Oceanolog. Hydrobiol. Stud. 34, 19-30.

Morales, Y., Weber, L.J., Mynett, A., Newton, E., 2006. Mussel dynamics model: a hydroinformatics tool for analyzing the effects of different stressors on the dynamics of freshwater mussel communities. Ecol. Modell. 197, 448-460.

Navarro, E., Bacardit, M., Caputo, L., Palau, A., Armengol, J., 2006. Limnological characterization and flow patterns of a three-coupled reservoir system and their influence on Dreissena polymorpha populations and settlement during the stratification period. Lake Reservoir Manage. 22, 293-302.

O'Neill, C.R. Jr., 1996. The Zebra Mussel. Impacts and Control. Cornell Cooperative Extensión. Information Bulletin 238. New York Sea Grant. Cornell Universituy. State University of New York. 62 pp.

Oreska, M.P.J., Aldrige, D.C., 2011. Estimating the financial cost of freshwater invasive species in Great Britain: a standardized approach to invasive species costing. Biol. Inv. 13, 305-319.

Palau, A., Cía, I., Fargas, D., Bardina, M., Massuti, S., 2003. Resultados preliminares sobre ecología básica y distribución del mejillón cebra en el embalse de RibaRoja (río Ebro). Monografía de Endesa. Dirección de Medio Ambiente y Desarrollo Sostenible. Endesa. Lleida.

Palau, A., Cía, I., Casas, R., Rosico, E., 2010. Zebra mussel distribution and habitat preference in the lower Ebro River (NE Spain). In: Van der Velde, G., Rajagopal y, S., Bij de Vaate, A. (Eds.), Zebra Mussel in Europe. Backhuys Publishers, Leiden, The Netherlands, pp. 113-118.

Păun, G., 1998. Computing with membranes. J. Comput. Syst. Sci. 61, 108-143.
Păun, G., Rozenberg, G., Salomaa, A., 2010. The Oxford Handbook of Membrane Computing. Oxford University Press, Oxford.

Pérez-Hurtado, I., Valencia-Cabrera, L., Pérez-Jiménez, M. J., Colomer, M. A., RiscosNúñez, A. 2010. MeCoSim: A general purpose software tool for simulating biological phenomena by means of $\mathrm{P}$ Systems. In IEEE Fifth International Conference on Bio-inpired Computing: Theories and Applications (BIC-TA 2010). IEEE, Inc. I, 637-643.

Petrie, S.A., Knapton, R.W., 1999. Rapid increase and subsequent decline in zebra and quagga mussels in Long Point Bay Lake Ere: possible influence of waterfowl predation. J. Great Lakes Res. 25, 772-782.

Pimentel, D., Zuniga, R., Morrison, D., 2005. Update on the environmental and economic costs associated with alien-invasive species in the United States. Ecol. Econ. 52, 273-288.

Ray, N., Burgman, M.A., 2006. Subjective uncertainties in habitat suitability models. Ecol. Modell. 195, 172-186.

Ruíz-Altaba, C., Jiménez, P.J., López, M.A., 2001. El temido mejillón cebra empieza a invadir los ríos españoles desde el curso bajo del río Ebro. Quercus 188, 50-51.

Sanz-Ronda, F.J., López, S., San Martín, S., Palau, A, 2013. Physical habitat of zebra mussel (Dreissena polymorpha) in the lower Ebro River (Northeastern Spain) Influence of hydraulic parameters in their distribution. Hydrobiologia doi: http://dx.doi.org/10.1007/s10750-013-1638-y.

Schneider, D.W., Ellis, C.D., Cummings, K.S., 1998. A transportation model assessment of the risk to native mussel communities from zebra mussel spread. Conserv. Biol. 12, 788-800.

Simberloff, D., Von Holle, B., 1999. Positive interactions of nonindigenous species: invasional meltdown? Biol. Invasions 1, 21-32.

Smit, H., Bij de Vaate, A., Fioole, A., 1992. Shell growth of the zebra mussel (Dreissena polymorpha (Pallas) in relation to select physiochemical parameters in the Lower Rhine and some associate lakes. Arch. Hydrobiol. 124, 257-280.

Sprung, M., 1992. Observations on shell growth and mortality of Dreissenc polymorpha in lakes. In: Neumann, D., Jenner, H.A. (Eds.), The Zebra Musse Dreissena Polymorpha, 4. Limnologie Aktuell, pp. 19-28.

Sprung, M., 1993. The other life: an account of present knowledge of the larval phase of Dreissena polymorpha. In: Nalepa, T.F., Scholoesser, D.W. (Eds.), Zebra Mussels: Biology, Impacts and Control. Lewis Publishers, pp. 39-53.

Strayer, D.L., Smith, L.C., 1996. Relationships between zebra mussels (Dreissen polymorpha) and unionid clams during the early stages of the zebra mussel invasion the Hudson River. Freshwater Biol. 36, 771-779.

Strayer, D., Malcom, H., 2006. Long-term demography of a zebra mussel (Dreissena polymorpha) population. Freshwater Biol. 51, 117-130.

Strayer, D.L., 2009. Twenty years of zebra mussels: lessons from the mollusk that made headlines. Front. Ecol. Environ. 7, 135-141.

Strayer, D.L., Cid, N., Malcom, H.M., 2010. Long-term changes in a population of an invasive bivalve and its effects. Oecologia 165, 1063-1072.

Ricciardi, A., 2001. Facilitative interactions among aquatic invaders: is an invasional meltdown occurring in the Great Lakes? Can. J. Fish. Aquat. Sci. 58, 2513-2525.

Stancykowska, A., 1977. Ecology of Dreissena polymorpha (Pall.) (Bivalva) in lakes. Archiv für Hydrobiology 115, 461-530.

Timar, L., Phaneuf, D.J., 2009. Modeling the human-induced spread of an aquatic invasive: the case of the zebra mussel. Ecol. Econ. 68, 3060-3071.

Van Nes, E.H., Scheffer, M., 2005. A strategy to improve the contribution of complex simulation models to ecological theory. Ecol. Modell. 185, 153-164.

Walz, N., 1978. The energy balance of the freshwater mussel Dreissena polymorpha Pallas in laboratory experiments and in lake Constance. II. Reproduction. Arch. Hydrobiol. 55, 106-119.

Ward, J.M., Ricciardi, A., 2007. Impacts of Dreissena invasions on benthic macroinvertebrate communities: a meta-analysis. Divers. Distrib. 13, 155-165.

Wolfram, S., 1994. Cellular Automata and Complexity: Collected Papers. Westview Press and IL Press, IL, USA. 